\title{
Prevalence, prenatal diagnosis and clinical features of oculo-auriculo-vertebral spectrum: a registry-based study in Europe
}

\author{
Ingeborg Barisic ${ }^{\star}, 1$, Ljubica Odak ${ }^{1}$, Maria Loane $^{2}$, Ester Garne ${ }^{3}$, Diana Wellesley ${ }^{4}$, Elisa Calzolari ${ }^{5}$, \\ Helen Dolk ${ }^{2}$, Marie-Claude Addor ${ }^{6}$, Larraitz Arriola ${ }^{7}$, Jorieke Bergman ${ }^{8}$, Sebastiano Bianca ${ }^{9}$, Berenice Doray ${ }^{10}$, \\ Babak Khoshnood $^{11}$, Kari Klungsoyr ${ }^{12}$, Bob McDonnell ${ }^{13}$, Anna Pierinii ${ }^{14}$, Judith Rankin ${ }^{15}$, Anke Rissmann ${ }^{16}$, \\ Catherine Rounding ${ }^{17}$, Annette Queisser-Luft ${ }^{18}$, Gioacchino Scarano ${ }^{19}$ and David Tucker ${ }^{20}$
}

Oculo-auriculo-vertebral spectrum is a complex developmental disorder characterised mainly by anomalies of the ear, hemifacial microsomia, epibulbar dermoids and vertebral anomalies. The aetiology is largely unknown, and the epidemiological data are limited and inconsistent. We present the largest population-based epidemiological study to date, using data provided by the large network of congenital anomalies registries in Europe. The study population included infants diagnosed with oculo-auriculovertebral spectrum during the 1990-2009 period from 34 registries active in 16 European countries. Of the 355 infants diagnosed with oculo-auriculo-vertebral spectrum, there were $95.8 \%(340 / 355)$ live born, $0.8 \%(3 / 355)$ fetal deaths, 3.4\% $(12 / 355)$ terminations of pregnancy for fetal anomaly and $1.5 \%(5 / 340)$ neonatal deaths. In $18.9 \%$, there was prenatal detection of anomaly/anomalies associated with oculo-auriculo-vertebral spectrum, $69.7 \%$ were diagnosed at birth, $3.9 \%$ in the first week of life and $6.1 \%$ within 1 year of life. Microtia (88.8\%), hemifacial microsomia (49.0\%) and ear tags (44.4\%) were the most frequent anomalies, followed by atresia/stenosis of external auditory canal (25.1\%), diverse vertebral (24.3\%) and eye (24.3\%) anomalies. There was a high rate (69.5\%) of associated anomalies of other organs/systems. The most common were congenital heart defects present in $\mathbf{2 7 . 8 \%}$ of patients. The prevalence of oculo-auriculo-vertebral spectrum, defined as microtia/ ear anomalies and at least one major characteristic anomaly, was 3.8 per 100000 births. Twinning, assisted reproductive techniques and maternal pre-pregnancy diabetes were confirmed as risk factors. The high rate of different associated anomalies points to the need of performing an early ultrasound screening in all infants born with this disorder.

European Journal of Human Genetics (2014) 22, 1026-1033; doi:10.1038/ejhg.2013.287; published online 8 January 2014

Keywords: oculo-auriculo-vertebral spectrum; epidemiology; congenital anomalies; Europe

\section{INTRODUCTION}

Oculo-auriculo-vertebral spectrum (OAVS) (OMIM 164210, OMIM 141400) is a complex developmental disorder that mainly affects head and neck structures derived from the first and second branchial arches and the intervening first pharyngeal pouch and branchial cleft. It is characterised by anomalies of the ear, hemifacial microsomia, epibulbar dermoids and vertebral anomalies. $^{1-3}$ Other terms, such as Goldenhar syndrome, hemifacial microsomia, lateral facial dysplasia, oculo-auriculo-vertebral dysplasia, facio-auriculo-vertebral spectrum/sequence and first and second branchial arch syndrome are also used, but it is now accepted that these conditions are part of the same clinical spectrum that varies from mild-to-severe phenotype. ${ }^{3-5}$

The causes of OAVS are unknown but undoubtedly complex and heterogeneous. Genetic as well as environmental causative factors have been proposed. Different chromosomal anomalies have been identified by standard karyotyping or array comparative genomic hybridisation in OAVS patients. ${ }^{6,7}$ The association with chromosomes $5,9,18,22$ and $\mathrm{X}$ was observed on several occasions. ${ }^{3}$ There are three reports that link OAVS with $14 \mathrm{q} 22.3-\mathrm{q} 23.3$ region. One patient and his father both had branchio-oto-renal syndrome and OAVS associated with an 11.79-Mb duplication of chromosome

${ }^{1}$ Children's Hospital Zagreb, Medical School University of Zagreb, Zagreb, Croatia; ${ }^{2}$ EUROCAT Central Registry, Room 12L09, University of Ulster, Ulster, Northern Ireland, UK; ${ }^{3}$ Pediatric Department, Hospital Lillebaelt, Kolding, Denmark; ${ }^{4}$ Wessex Clinical Genetics Service, Princess Anne Hospital, Southampton, UK; ${ }^{5}$ Registro IMER, Azienda Ospedaliero-Unifersitaria di Ferrara, Ferrara, Italy; ${ }^{6}$ Autonome de Genetique Medicale, Lausanne, Switzerland; ${ }^{7}$ Registro Anomalias Congenitas CAV, Direccion de Salud Publica, Donostia San Sebastian, Spain; ${ }^{8}$ Eurocat Registration Northern Netherlands, Department of Genetics, University Medical Center Groningen, Groningen, The Netherlands; ${ }^{9}$ Genetica Medica, ARNAS Garibaldi, ARNAS Garibaldi, Catania, Italy; ${ }^{10}$ Service de genetique Medicale, Hopitale de Hautepierre, Strasbourg Cedex, France; ${ }^{11}$ Paris Registry of Congenital Malformations, INSERM U953, Maternite de Port-Royal, Paris, France; ${ }^{2}$ Medical Birth Registry of Norway, Norwegian Institute of Public Health, and Department of Public Global Health and Primary Health Care, University of Bergen, Bergen, Norway; ${ }^{13}$ Health Information Unit, Health Service Executive, Dr Steevens Hospital, Dublin, Ireland; ${ }^{14}$ CNR Institute of Clinical Physiology, Pisa, Italy; ${ }^{15}$ Institute of Health and Society Newcastle University, Newcastle upon Tyne, UK; ${ }^{16}$ Malformation Monitoring Centre SaxonyAnhalt, Medical Faculty Otto-von-Guericke University, Magdeburg, Germany; ${ }^{17}$ National Perinatal Epidemiology Unit, University of Oxford, Oxford, UK; ${ }^{18}$ Universitatskinderklinik Mainz, Mainz, Germany; ${ }^{19}$ Registro Campano Difetti Congeniti, Azienda Ospedaliera "G Rummo", Benevento, Italy; ${ }^{20}$ Congenital Anomaly Register and Info Service Public Health Level 3 West Wing, Singleton Hospital, Wales, UK

*Correspondence: Dr I Barisic, Department of Paediatrics, Children's Hospital Zagreb, Medical School University of Zagreb, Klaiceva 16, Zagreb 10 000, Croatia. Tel: +385 14600 107; Fax: +385 14600 160; E-mail: ingeborg.barisic@kdb.hr

Received 1 June 2013; revised 2 November 2013; accepted 9 November 2013; published online 8 January 2014 
14q22.3-q23.3 and a 4.38-Mb deletion in $13 \mathrm{q} 21.31-\mathrm{q} 21.32 .{ }^{8}$ Northrup et $a l^{9}$ have described a patient with per $\operatorname{inv}(14)(\mathrm{p} 11.2 \mathrm{q} 22.3)$ inherited from his phenotypically normal mother. Recent publication describes a new familial 14q23.1 duplication, $1.34 \mathrm{Mb}$ in size, which segregates with the OAVS phenotype in an autosomal dominant manner. ${ }^{10}$ These findings indicate that disruption of potential candidate gene/ genes in 14q22.3-q23.3 region could be a causative factor in at least some of the OAVS cases. A genome-wide linkage analysis in one family identified Goosecoid mapped at $14 \mathrm{q} 32.1$ as a possible candidate gene, but no pathogenetic mutation was found. ${ }^{11} \mathrm{~A}$ more recent genome-wide association study also failed to identify a clear causative variant. ${ }^{12}$ Fischer et al ${ }^{13}$ found abnormal expression of BAPX1 gene (mapped at $4 \mathrm{p} 15.3$ ) in a significant number of OAVS patients and suggested that epigenetic disregulation of BPAX1 and possibly other genes might have a role in the aetiology of OAVS. The epigenetic changes could explain the higher incidence of twinning, high proportion of discordant monozygotic twins and high correlation of use of in vitro fertilisation in OAVS. ${ }^{14}$

The condition usually occurs sporadically, but familial cases compatible with autosomal dominant ${ }^{15,16}$ and autosomal recessive ${ }^{2,17}$ types of inheritance have been described. The possibility of germinal mosaicism has also been considered. ${ }^{18}$ The low empiric recurrence risk of $2-3 \%$ and the rarity of reports of concordance in twins support the multifactorial type of inheritance in most cases. ${ }^{3}$

The OAVS has been linked with intrauterine exposure to many different drugs. In particular, maternal use of vasoactive medications in combination with cigarette smoking in the first trimester was found to be associated with an increased risk of OAVS. ${ }^{19}$ Vasoactive medications reported more often in OAVS pregnancies compared with controls include pseudoephedrine, phenylpropanolamine, aspirin, and ibuprofen, but clear association was demonstrated only for pseudoephedrine. ${ }^{19}$ Severe manifestations of OAVS were also observed in a cocaine-exposed infant. ${ }^{20}$

In fact, it was previously suggested that disturbance in vascular supply to cephalic neural crest cells could hinder embryonic development in the branchial arches and cause OAV spectrum. ${ }^{21}$

Twin pregnancies ${ }^{19,22,23}$ and the use of artificial reproductive techniques (ART) $)^{14,24}$ have been observed more often than expected among OAVS patients. The relationship with maternal diabetes contributes additionally to the heterogeneity of environmental causes associated with OAVS. ${ }^{25}$ As the aetiology is largely unknown, data on the possible environmental risk factors from epidemiological studies are needed.

Although several large clinical series of OAVS patients have been published discussing the classification, clinical presentation, diagnostic criteria and associated findings, ${ }^{2,4,5}$ population-based epidemiological studies on OAVS are lacking, because they demand large populations, standardised data collection and genetic expertise. There has been considerable discrepancy in the reported prevalence rates that range from 1 per $5642^{2}$ to 1 per $45000 .^{26}$ Most data are based on live born (LB) children, while little is known about fetal deaths (FDs) and terminations of pregnancy for fetal anomaly (TOPFA) after prenatal ultrasound diagnosis. In addition, hospitalbased series of patients from specialised centres bring ascertainment biases in prevalence data and frequency of associated abnormalities.

In this study, we used data from EUROCAT, a large network of population-based congenital anomaly registries in Europe, to provide population-based information on OAVS patients, including the total prevalence and birth outcomes (proportion of LB, FD at gestational age (GA) $\geq 20$ weeks, TOPFA), time of diagnosis, sex, GA and weight at birth, associated anomalies, family history, consanguinity and possible risk factors. To our knowledge, this is the largest series of OAVS patients published so far.

\section{MATERIAL AND METHODS}

The EUROCAT congenital anomaly registries are surveying $>1.7$ million births per year (30\% of the annual European birth population). They collect data on all major structural congenital anomalies, chromosomal abnormalities and genetic syndromes for all birth outcomes. The registries are based on multiple sources of information that include hospital records, birth and death certificates, cytogenetic reports and post mortem examinations. A detailed description of registries, methods of case ascertainment, data collection and processing is available elsewhere ${ }^{27}$ (http://www.eurocat-network.eu/content/ DQI-2010.pdf). For the purpose of this study, we used data provided by 34 registries from 16 European countries for the 1990-2009 period. Data was extracted from the central database in January 2013.The central EUROCAT database was searched for ICD9/BPA (756060, 75606), ICD10/BPA (Q8704) and OMIM $(164210,141400)$ codes assigned to cases of OAVS/Goldenhar/ hemifacial microsomia. For the inclusion in the study or minimal diagnostic criteria, we used arbitrary definition of the presence of microtia/ear anomalies and at least one major anomaly of the OAV spectrum. Isolated cases of microtia or other minor craniofacial anomalies specified in the Minor Anomalies for Exclusion list in the EUROCAT classification guidelines (www.eurocat-network.eu/content/EUROCAT-Guide-1.3.pdf) were not included. EUROCAT registries do not collect data on laterality of malformations or zygosity, thus we were not able to analyse our data set in this respect. An associated anomaly was defined as a major structural anomaly other than craniofacial and vertebral anomalies, which are usually considered to be part of the classical OAVS. In 20/30 (66.6\%) of EUROCAT registries, clinical geneticists take part in the examination of most or all patients with dysmorphic features and multiple anomalies, and in the remaining registries clinical geneticists participate in the examination of selected cases. Medical geneticist (IB) reviewed all records. Textual description was also analysed in order to ensure all relevant clinical information. Local registries were occasionally contacted for supplying additional information. All phenotype and epidemiological data will be available to all phenotypic databases (eg, OMIM or GeneReviews).

\section{Statistical analysis}

Descriptive data are presented as counts and percentages for categorical data, and mean and $95 \%$ confidence interval based on Poisson's distribution is used for prevalence. Statistical testing was performed at $P=0.05$ level of statistical significance. Generalised Linear/Nonlinear model based on Poisson's distribution was used for statistical testing of time trends in prevalence, Fisher's exact test for testing difference between categorical data and difference between two proportions' test for statistical testing between prenatal diagnosed and nondiagnosed patients. Chi-squared test was performed in order to determine differences in maternal age distribution between OAVS and other EUROCAT cases.

\section{RESULTS}

We recorded a total of 355 cases of OAVS during the 20 years of study period. There were $95.8 \%(340 / 355) \mathrm{LB}, 0.8 \%$ (3/355) FDs, $3.4 \%$ $(12 / 355)$ TOPFA and $1.5 \%$ (5/340) neonatal deaths (Table 1$)$. Of the 307 patients with a known time of diagnosis, $69.7 \%$ were diagnosed at birth, 3.9\% in the first week of life and $6.1 \%$ within 1 year of life. In $18.9 \%$, there was a prenatal detection of congenital anomaly/ anomalies, followed by the diagnosis of OAVS later on. The number of prenatally detected cases increased to some extent from1990-1999 to 2000-2009 period, although not significantly $(P=0.27)$ (Table 1$)$. The mean GA at discovery of an anomaly by prenatal ultrasound was $21.3 \pm 4.1$ (range 11-40) gestational weeks. Of the 58 prenatally detected patients, there were $45 \mathrm{LB}, 1 \mathrm{FD}$ and 12 (20.7\%) pregnancies were terminated at $22.1 \pm 4.8$ (range 17-36) gestational weeks. 
Table 1 Prenatal detection rate and outcome of pregnancies with oculo-auriculo-vertebral spectrum (OAVS) in the EUROCAT registries, 1990-2009

\begin{tabular}{|c|c|c|c|c|c|c|c|}
\hline Monitored period & Total births & $\begin{array}{l}\text { Total no. } \\
\text { of patients }\end{array}$ & $\begin{array}{c}\text { Prenatally detected/number of } \\
\text { patients with available data }\end{array}$ & $\begin{array}{l}\text { Prenatal detection rate, } \\
\text { (\%) } 95 \% \mathrm{Cl}\end{array}$ & $\angle B$ & $F D$ & TOPFA \\
\hline 1990-1999 & 4639123 & 125 & $18 / 113$ & $15.9(10.0-24.3)$ & 119 & 2 & 4 \\
\hline 1990-2009 & 13753506 & 355 & $58 / 307$ & $18.9(14.8-23.8)$ & 340 & 3 & 12 \\
\hline
\end{tabular}

Abbreviations: FD, fetal death; LB, live born; TOPFA, terminations of pregnancy for fetal anomaly.

The diagnosis was confirmed by post mortem examination in 13 cases. Prenatally suspected cases had a higher frequency of central nervous system $(P=0.001)$, congenital heart $(P=0.009)$, genitourinary $(P=0.001)$ and spine $(P=0.02)$ anomalies compared with those who had negative prenatal ultrasound scan. In addition, there were significantly more cases with two or more major congenital anomalies compared with patients who were detected after birth $(P=0.004)$. In $16 / 108(14.8 \%)$ cases, a major structural anomaly was detected postnatally following a negative prenatal ultrasound result.

Detailed clinical description was available for 259 patients, and the frequencies of observed anomalies are presented in Table 2. Microtia (88.8\%), hemifacial microsomia $(49.0 \%)$ and ear tags $(44.4 \%)$ were most frequent, followed by atresia/stenosis of external auditory canal $(25.1 \%)$, diverse vertebral $(24.3 \%)$ and eye $(24.3 \%)$ anomalies and orofacial clefts $(17.8 \%)$.

There were 180 (69.5\%) OAVS patients with anomalies other than craniofacial and vertebral anomalies, which are usually considered to be part of classical OAVS. One associated major anomaly was present in $111(61.7 \%)$, two anomalies in $54(30 \%)$ and three or more associated anomalies in $15(8.3 \%)$ patients. The most common anomaly was congenital heart defect present in $72(27.8 \%)$ patients. The frequency of a particular type of cardiac anomalies did not differ from the frequency in the general population of the EUROCAT registries included in the study for the same period, with the exception of conotruncal defects $(P=0.02)$. Congenital heart defects were not significantly associated with pulmonary $(P=0.68)$ or renal $(P=0.34)$ abnormalities.

\section{Epidemiological data}

Prevalence was calculated based on data from 16 registries with nonchromosomal syndrome prevalence above the EUROCAT average of 7.8 per 1000 in order to secure a high rate of ascertainment of cases (http://www.eurocat-network.eu/content/DQI-2010.pdf). In the period from January 1990 to December 2009 in these registries, we recorded 161 cases in the population of 4245519 births. The estimated prevalence is thus 1 per 26370 or 3.8 per 100000 births. The prevalence rates for 1990-1999 and 2000-2009 were 2.8 and 4.3 per $100000(P=0.008)$, respectively (Table 3$)$.

The characteristics of OAVS patients observed in all 34 registries are shown in Table 4. The male-to-female ratio was 1.4:1. The mean GA in live births was $38.1 \pm 6.2$ in females and $38.9 \pm 4.1$ in males, while the mean birth weight was $2971 \pm 769 \mathrm{~g}$ in females and $2940 \pm 769 \mathrm{~g}$ in males.

The mean maternal age was $29.9 \pm 4.8$ years and the mean paternal age $32.1 \pm 6.4$ years. Comparison of the maternal age distribution with the maternal age distribution in the total EUROCAT population (data known for $67.6 \%$ of the EUROCAT total birth population) yielded a significant difference $(P=0.04)$, mothers of OAVS patients being more represented in the $\geq 30$-year-old group compared with the rest of EUROCAT population.
There were 11 confirmed familial OAVS cases, 3 of these among sibs and 8 cases where one of the parents was affected. No phenotypic differences between familial and sporadic cases were observed. Parental consanguinity was recorded in two cases.

Karyotyping was performed in $54.8 \%(155 / 283)$ of cases and yielded two abnormal findings (47,XXY and $45, \mathrm{X} / 46, \mathrm{XY})$. Data on FISH analyis for del22q11.2 were not available.

No evidence of exposure to consistent teratogenic agents was noted, including data on medications that were available for 70 patients. The use of vasoactive drugs was recorded in six cases. Multiple pregnancies of undetermined zygosity were recorded in 25 (7.2\%) cases (in all cases, only one affected of twins/triplets), and $15 / 172(8.7 \%)$ patients were conceived by one of the methods of ART. Maternal diabetes was present in $3.9 \%(6 / 152)$ of the affected pregnancies (Table 4).

\section{DISCUSSION}

\section{Prevalence}

The usually cited prevalence of OAVS is 1 per $5600,{ }^{2}$ although others have suggested much lower figures in the range of 1 per $10000,{ }^{30}$ 1 per $19500,{ }^{31} 1$ per $26550^{32}$ to 1 per $45000 .^{26}$ The prevalence of 1 per 26370 found in our study is more in line with these results. The observed significant increase in the prevalence observed comparing 1990-1999 and 2000-2009 may be due to the better ascertainment of cases or to the true increase in prevalence of this condition and should be investigated further.

There is no universal agreement upon minimal diagnostic criteria for OAVS, but an ear anomaly has been suggested by some authors as the mildest form..$^{2-5,19}$ As EUROCAT registries do not record cases with isolated minor anomalies of the head and neck, our series of OAVS patients did not include the possible mild cases presenting only as microtia or some other minor/cosmetic ear defect. According to our case definition, only patients with ear anomaly and at least one major craniofacial and/or vertebral feature involved in OAVS were included in the study. Therefore, the prevalence of 1 per 26370 in EUROCAT registries represents a minimum figure and refers to a clinically relevant/serious group of patients. In addition, OAVS patients who are diagnosed at a later age will be missed, as some registries only register cases with anomalies discovered in the neonatal period.

\section{Clinical features}

Premature birth, low birth weight and failure to thrive have been often reported in infants with OAVS. In a demographic study of OAVS, Werler et $a l^{23}$ found that $20 \%$ of cases weighed $<2500 \mathrm{~g}$ at birth, compared with only $5 \%$ of controls. In our patient series, $20.8 \%$ of males and $36.7 \%$ of females weighed $<2500 \mathrm{~g}$. More than two-thirds of both sexes had normal GA at birth. The observed male preponderance is in accordance with observations from previous studies. ${ }^{3-5,19}$

The diagnosis of OAVS relies on the recognition of the characteristic craniofacial, ear, eye and vertebral defects and in most cases is 
Table 2 Type and frequency of anomalies among patients with oculo-auriculo-vertebral spectrum (OAVS)

\begin{tabular}{|c|c|c|c|c|c|}
\hline Type of anomaly & $\begin{array}{c}\text { Patients } \\
\mathrm{N}=259(\%)\end{array}$ & $\begin{array}{l}\text { Rollnick et al, } 4 \\
\qquad \mathrm{~N}=294\end{array}$ & $\begin{array}{l}\text { Vento et al, } \\
\qquad \mathrm{N}=154\end{array}$ & $\begin{array}{l}\text { Tasse et al, } \\
\mathrm{N}=53\end{array}$ & $\begin{array}{c}\text { Toulitaou et al, } \\
\qquad \mathrm{N}=17\end{array}$ \\
\hline Ear & $259(100)$ & $294(100)$ & & $53(100)$ & $17(100)$ \\
\hline Microtia/misshapen/dysplastic/rudimentary ear ${ }^{a}$ & $230(88.8)$ & & & & $16(94)$ \\
\hline Preauricular skin tag ${ }^{a}$ & $115(44.4)$ & & $61(39.6)$ & & $10(59)$ \\
\hline Atresia/stenosis of external auditory canal & $65(25.1)$ & & & & $9(53)$ \\
\hline Absence of auricle & $24(9.3)$ & & & & \\
\hline Accessory auricle & $23(8.9)$ & & & & \\
\hline Anotia & $17(6.6)$ & & & & \\
\hline Preauricular pits/sinus ${ }^{a}$ & $6(2.3)$ & & & & \\
\hline Other & $17(6.6)$ & & & & \\
\hline Eye & $63(24.3)$ & $52(18)$ & & $13(24.5)^{\mathrm{b}}$ & $11(65)$ \\
\hline Epibulbar dermoids & $20(7.7)$ & $9(4.4)$ & $32(20.7)$ & $11(20.7)$ & $2(12)$ \\
\hline Epicanthus $^{\mathrm{a}}$ & $14(5.4)$ & & & & $12(75)$ \\
\hline Microphthalmia & $14(5.4)$ & & & $5(9.4)$ & $6(35)$ \\
\hline Coloboma of eyelid & $10(3.9)$ & & & $4(7.5)$ & $2(12)$ \\
\hline Coloboma of iris & $4(1.5)$ & & & & $1(6)$ \\
\hline Anophthalmia & $4(1.5)$ & & & $2(3.7)$ & \\
\hline Aniridia & $1(0.4)$ & & & & \\
\hline Absence of lens & $1(0.4)$ & & & & \\
\hline Other & $8(3.1)$ & & & & \\
\hline Orofacial clefts & $46(17.8)$ & $66(22)$ & & $21(40)$ & $5(29)$ \\
\hline Cleft lip and palate & $21(8.1)$ & $21(7)$ & & $5(9.4)$ & \\
\hline Cleft palate & $17(6.6)$ & $45(15)$ & & $5(9.4)$ & \\
\hline Cleft lip & $7(2.7)$ & & & $2(3.7)$ & \\
\hline Orofacial clefts, other & $11(4.2)$ & & & $9(16.9)$ & \\
\hline Face and neck & $145(56.0)$ & & & & $13(76)$ \\
\hline $\begin{array}{l}\text { Hemifacial microsomia, including asymmetry } \\
\text { of the face }{ }^{a} \text {, micrognathia, mandibular } \\
\text { hypoplasia, and anomalies of jaw size }\end{array}$ & $127(49.0)$ & $202(68.7)$ & & $44(83)$ & $10(59)$ \\
\hline Anomalies of the nose & $9(3.5)$ & & & & $1(6)$ \\
\hline Facial palsy & $9(3.5)$ & & $24(45)$ & & \\
\hline Branchial cyst ${ }^{a}$ & $9(3.5)$ & & & & \\
\hline Macrostomia & $6(2.3)$ & & $95(61.6)$ & & \\
\hline Tongue anomaly & $4(1.5)$ & & & & \\
\hline Vertebral & $63(24.3)$ & $55(18.7)$ & $29(18.8)$ & $10(19)$ & $3(18 \%)$ \\
\hline Cervical & $17(6.6)$ & & & & \\
\hline Cervical anomaly NOS & $10(3.9)$ & & & & \\
\hline Hemivertebre cervical & $4(1.5)$ & & & & \\
\hline Split cervical vertebrae & $1(0.4)$ & & & & \\
\hline Fussed cervical vertebrae & $2(0.8)$ & & & & \\
\hline Thoracic/lumbar/sacral & $13(5.0)$ & & & & \\
\hline Thoracic vertebrae anomaly NOS & $8(3.1)$ & & & & \\
\hline Lumbar vertebrae anomaly NOS & $2(0.8)$ & & & & \\
\hline Accessory lumbar vertebrae & $1(0.4)$ & & & & \\
\hline Agenesis lumbar vertebrae & $1(0.4)$ & & & & \\
\hline Sacral agenesis & $1(0.4)$ & & & & \\
\hline Hemivertebrae NOS & $14(5.4)$ & & & & \\
\hline Spine scoliosis & $8(3.1)$ & & & & \\
\hline Spine NOS & $18(6.9)$ & & & & \\
\hline Rib anomalies & $18(6.9)$ & & $12(7.8)$ & & \\
\hline Congenital heart defects & $72(27.8)$ & $14(5)$ & & $8(15)$ & $3(18)$ \\
\hline Ventricular septal defect & $31(12.0)$ & & & $5(9.4)$ & \\
\hline Atrial septal defect & $13(5.0)$ & & & & \\
\hline
\end{tabular}


Table 2 (Continued)

\begin{tabular}{|c|c|c|c|c|c|}
\hline Type of anomaly & $\begin{array}{c}\text { Patients } \\
\mathrm{N}=259 \text { (\%) }\end{array}$ & $\begin{array}{l}\text { Rollnick et al, }{ }^{4} \\
\qquad \mathrm{~N}=294\end{array}$ & $\begin{array}{l}\text { Vento et } a,{ }^{28} \\
\qquad \mathrm{~N}=154\end{array}$ & $\begin{array}{l}\text { Tasse et al, } \\
\quad \mathrm{N}=53\end{array}$ & $\begin{array}{c}\text { Toulitaou et al, } \\
\qquad \mathrm{N}=17\end{array}$ \\
\hline Pulmonary valve stenosis & $8(3.1)$ & & & & \\
\hline Dextrocardia & $6(2.3)$ & & & $1(1.8)$ & \\
\hline Transposition of great arteries & $4(1.5)$ & & & & \\
\hline Tetralogy of Fallot & $4(1.5)$ & & & & \\
\hline Hypoplastic aorta & $3(1.2)$ & & & & \\
\hline Double outlet right ventricle & $2(0.8)$ & & & & \\
\hline Hypoplastic left heart syndrome & $1(0.4)$ & & & & \\
\hline Aortopulmonary window & $1(0.4)$ & & & & \\
\hline Abnormal subclavian artery & $1(0.4)$ & & & & \\
\hline Lobar anomaly of the lungs & $4(1.5)$ & & & & \\
\hline Lung hypoplasia & $4(1.5)$ & & & & \\
\hline Tracheomalacia ${ }^{a}$ & $1(0.4)$ & & & & \\
\hline Laryngomalacia $^{a}$ & $1(0.4)$ & & & & \\
\hline Digestive system & $20(7.7)$ & $6(2)$ & & & $2(12)$ \\
\hline Oesophageal atresia with tracheo-oesophageal fistula & $7(2.7)$ & & & & \\
\hline Anorectal stenosis/atresia & $4(1.5)$ & & & & \\
\hline Imperforate anus & $3(1.2)$ & & & & \\
\hline Diaphragmatic hernia & $2(0.8)$ & & & & \\
\hline Pyloric stenosis ${ }^{\mathrm{a}}$ & $2(0.8)$ & & & & \\
\hline Annular pancreas & $1(0.4)$ & & & & \\
\hline Hypospadias & $7(2.7)$ & & & $2(3.7)$ & \\
\hline Cystic kidney & $3(1.2)$ & & & & \\
\hline Horseshoe kidney & $2(0.8)$ & & & & \\
\hline Duplex kidney & $1(0.4)$ & & & & \\
\hline Cyst of urachus & $1(0.4)$ & & & & \\
\hline Limb defects & $30(11.6)$ & $33(11)$ & $26(16.8)$ & $6(11.3)$ & $4(23)$ \\
\hline Polydactyly & $7(2.7)$ & & & & \\
\hline Radial defects of hands & $6(2.3)$ & & & & \\
\hline Congenital hip dislocation & $5(1.9)$ & & & & \\
\hline Pes equinovarus & $4(1.5)$ & & & & \\
\hline Syndactyly & $4(1.5)$ & & & & \\
\hline Bifid thumb & $3(1.2)$ & & & & \\
\hline Camptodactyly & $2(0.8)$ & & & & \\
\hline Low set thumbs ${ }^{\mathrm{a}}$ & $2(0.8)$ & & & & \\
\hline Pes calcaneovalgus & $1(0.4)$ & & & & \\
\hline Forearm anomalies NOS & $3(1.2)$ & & & & \\
\hline Nervous system & $27(10.4)$ & $38(13)$ & & $8(15)$ & $5(29)^{c}$ \\
\hline Neural tube defects (including encephalocele) & $6(2.3)$ & & & & \\
\hline Hydrocephaly & $5(1.9)$ & & & $1(1.8)$ & \\
\hline Ventriculomegaly & $5(1.9)$ & & & $1(1.8)$ & \\
\hline
\end{tabular}


Table 2 (Continued)

\begin{tabular}{|c|c|c|c|c|c|}
\hline Agenesis of corpus callosum & $5(1.9)$ & & & & \\
\hline Cerebral cyst & $2(0.8)$ & & & & \\
\hline Aqueductus stenosis & $1(0.4)$ & & & & \\
\hline Cerebral anomaly NOS & $4(1.5)$ & & & & \\
\hline Situs viscerum inversus & $1(0.4)$ & & & & \\
\hline
\end{tabular}

Abbreviation: NOS, not otherwise specified; individuals with more than one anomaly within a category were counted only once.

aThese anomalies are considered minor according to the EUROCAT criteria and not are not systematically recorded in some registries.

Epibulbar dermoids excluded.

'Facial nerve palsy included.

Table 3 Prevalence of oculo-auriculo-vertebral spectrum (OAVS) in 16 selected EUROCAT registries, 1990-2009

\begin{tabular}{lccc}
\hline Monitored period & Total births & $\begin{array}{c}\text { Total no. of } \\
\text { patients }\end{array}$ & $\begin{array}{c}\text { Birth prevalence per } \\
100000(95 \% \text { Cl) }\end{array}$ \\
\hline $1990-1999$ & 1775132 & 49 & $2.8(2.1-3.7)$ \\
2000-2009 & 2596179 & 112 & $4.3(3.6-5.2)$ \\
$1990-2009$ & 4245519 & 161 & $3.8(3.2-4.4)$ \\
\hline
\end{tabular}

quite straightforward in spite of the clinical variability and possible overlap with other entities (eg, CHARGE syndrome, Treacher Collins syndrome, VACTERL association). Ear anomalies were present in all recorded patients, ranging from mild deformities in the size and shape of the external ear, preauricular tags and pits to anotia. The frequency and type of ear anomalies, facial asymmetry and eye anomalies are similar to data reported by others. ${ }^{4,5}$

Vertebral defects were reported in $18-60 \%$ of patients with OAVS. ${ }^{2,4,5,28,29,33}$ The frequency of spine anomalies in previously published OAVS cohorts depends on the sample size, patient selection and the level of spine investigation. We recorded spinal anomalies in $24.3 \%$ of cases. Vertebral anomalies occurred at all levels of spinal column, although slightly more frequently in the cervical region. The association of ocular and vertebral anomalies reported by Gibson et $a l^{33}$ was not observed.

\section{Associated anomalies}

We found $69.4 \%$ of OAVS patients to have associated anomalies. This is the highest rate of anomalies not involving the head, neck and vertebral column reported in OAVS so far. The high rate of associated anomalies can be explained by the fact that we were able to present data on all types of birth, including TOPFA, FD and early deaths. In addition, existing studies have been small and/or from specialised centres, which can cause ascertainment bias towards a specific group of anomalies. There are only two detailed clinical reports with a large number of patients. $\mathrm{Grabb}^{2}$ has reported seven associated anomalies among 102 patients. Here the under-reporting could be due to the limited diagnostic possibilities in those times. Rollnick et al ${ }^{4}$ found $44 \%$ of associated anomalies in a large series of 294 patients, but the study included mild cases, with isolated microtia being present in $31 \%$ of cases. Excluding these, the proportion of associated anomalies would be in line with our findings.

We observed not only a high rate but also a vast range of defects of different organs and systems. The most frequent associated anomalies were congenital heart defects present in almost one-third of patients. The reported prevalence of congenital heart defects among OAVS patients ranges from 1 to $58 \%$. $^{2,4,26,29,34}$ These differences are related to the sample size and different methodology of respective studies. $\mathrm{Grabb}^{2}$ found only one heart anomaly among 102 patients. Rollnick et $a l^{4}$ included mild cases and found that only 4 and $5 \%$ of cases had a congenital heart defect, respectively. On the other hand, heart defects were found in a half of patients in the series coming from cardiac department. ${ }^{35}$ In our study, the conotruncal anomalies were significantly associated with OAVS as observed previously by some authors, ${ }^{34,36}$ while the prevalence of other types of congenital heart defects did not differ from the EUROCAT general population. The congenital heart defects were not associated with pulmonary and renal abnormalities, as observed by Kumar et al. ${ }^{36}$

Genitourinary malformations were the second most common group of anomalies in our cohort $(15.8 \%)$, with renal agenesis and ureteral anomalies being most frequent. The presence of genitourinary defects reported in OAVS patients ranges from $2-5 \%{ }^{2,4}$ to $50 \%$ in a small study where 14 urinary tract anomalies (of these five cases of renal agenesis) were diagnosed in 28 children with OAVS by performing imaging of the urinary tract. ${ }^{37}$ This indicates that a more detailed investigation may reveal that genitourinary anomalies are more common than expected.

The frequency of central nervous system anomalies found in our study $(10.4 \%)$ is lower than that described in the literature, where frequencies were reported that range between 13 and $47 \%{ }^{4,5,38}$ The highest frequency was found by Rosa et a ${ }^{38}$ who included only subjects undergoing neuroimaging and detected anomalies in $47 \%$ of patients. We did not confirm the association between central nervous system anomalies and ophthalmologic anomalies observed previously. ${ }^{5,38}$

OAVS with radial defect (OMIM 141400), which is considered a separate entity among OAVS, was present in only six patients. In our data set, we did not find cases that were diagnosed as oculo-auriculofronto-nasal syndrome (OMIM (\%601452), a rare developmental field defect that combines abnormal development of the first and second branchial arches with abnormal morphogenesis of the frontonasal and maxillary processes. ${ }^{39,40}$

The broad spectrum of associated major anomalies reinforces the heterogeneity of OAVS supporting the hypothesis that OAVS could be part of the axial mesodermal dysplasia spectrum. ${ }^{41}$

\section{Prenatal diagnosis}

In order to delineate the pattern of anomalies detected prenatally in OAVS, Castori et $a l^{42}$ reviewed prenatal ultrasound findings in 20 previously reported cases. They found asymmetric facial defects 
Table 4 Descriptive epidemiological data on patients with oculoauriculo-vertebral spectrum (OAVS) in the EUROCAT registries, 1990-2009

\begin{tabular}{|c|c|c|}
\hline Characteristics & \multicolumn{2}{|c|}{$\begin{array}{c}\text { Number of OAVS } \\
\text { patients (\%) }\end{array}$} \\
\hline \multicolumn{3}{|l|}{ Sex } \\
\hline Male & \multicolumn{2}{|c|}{205} \\
\hline Female & \multicolumn{2}{|c|}{148} \\
\hline \multirow[t]{2}{*}{ Unknown } & \multicolumn{2}{|c|}{2} \\
\hline & \multicolumn{2}{|c|}{$\mathrm{n}=321$ (live births with known } \\
\hline \multirow[t]{3}{*}{ Gestational age, week } & \multicolumn{2}{|c|}{ gestational age and sex) } \\
\hline & M & $\mathrm{F}$ \\
\hline & $n=188$ & $n=133$ \\
\hline$<37$ & $33(17.5 \%)$ & $21(15.8 \%)$ \\
\hline $37-41$ & $147(78.2 \%)$ & $105(78.9 \%)$ \\
\hline$\geq 42$ & $8(4.3 \%)$ & $7(5.3 \%)$ \\
\hline \multirow[t]{3}{*}{ Birth weight (g) } & \multicolumn{2}{|c|}{$\begin{array}{c}\mathrm{n}=320 \text { (live births with known } \\
\text { gestational age and sex) }\end{array}$} \\
\hline & M & F \\
\hline & $n=192$ & $n=128$ \\
\hline$<1500$ & $9(4.7 \%)$ & $13(10.1 \%)$ \\
\hline 1500-1999 & $13(6.8 \%)$ & $7(5.5 \%)$ \\
\hline 2000-2499 & $18(9.3 \%)$ & $27(21.1 \%)$ \\
\hline 2500-2999 & $39(20.3 \%)$ & $28(21.9 \%)$ \\
\hline 3000-3499 & $71(37 \%)$ & $41(32 \%)$ \\
\hline$>3500$ & 42 (21.9\%) & $12(9.4 \%)$ \\
\hline Positive family history & $11 / 196(5.6 \%)$ & \\
\hline Consanguinity & 2/202 (1\%) & \\
\hline Singleton pregnancies & $322 / 347(92.8 \%)$ & \\
\hline ART & $10 / 158(6.3 \%)$ & \\
\hline Multiple pregnancies & $\begin{array}{l}25 / 347 \text { (23 twins, } \\
2 \text { triplets) }(7.2 \%)\end{array}$ & \\
\hline ART & $5 / 14(35.7 \%)$ & \\
\hline $\begin{array}{l}\text { Maternal pregestational } \\
\text { diabetes }\end{array}$ & $6 / 152(3.9 \%)$ & \\
\hline
\end{tabular}

Abbreviation: ART, assisted reproductive technology.

and central nervous system anomalies to be the most common findings. In our group of OAVS patients, prenatally observed anomalies were rather heterogeneous, affecting not only craniofacial structures but also other organs and systems. In more severe cases, the prenatal diagnosis is possible as early as from 11 weeks of gestation.

\section{Possible aetiology and risk factors}

The aetiological heterogeneity and complexity of OAVS has been suggested in many reports. Previous studies have occasionally identified chromosomal abnormalities associated with OAVS. We identified one patient with $47, \mathrm{XXY}$ and one with $45, \mathrm{X} / 46, \mathrm{XY}$. Sex chromosome aneuploidies have been described on several occasions in patients with $\mathrm{OAVS}^{5,43,44}$ but as these aneuploidies are quite frequent, the association with OAVS is possibly due to chance.
Although most cases were sporadic, $5.6 \%$ cases were familial, confirming the existence of a small proportion of families with a high recurrence risk.

Twin pregnancies were, on average, five times more common in OAVS patients compared with the incidence of twin pregnancies in European countries who participated in the study (the mean rate of twin pregnancies was 14.9 per 1000 births, ranging from 11.2 in Italy to 18.0 in Denmark). ${ }^{45}$ Several studies have reported an increased rate of twinning in pregnancies with OAVS with and without infertility treatment. Different possible mechanisms, including basic common embryological, disruptive or epigenetic events, were discussed. ${ }^{14,22,23,26}$ Because multiple gestations occur commonly in couples treated for infertility, we also examined the use of ART. Couples who had children with OAVS were treated more for infertility than the general European population (15/172 or $8.7 \%$ compared with the mean use of ART of 2.7\%; range 1.2-4.9\% in European countries under study). ${ }^{46}$ An excess of patients with OAVS conceived by ART has been also described before. ${ }^{14,47-49}$ At present, it is not known whether the observed increased risk is due to the technique itself or to the fertility problems in parents. ${ }^{14}$ Our data confirm the observation that twinning and treatment for infertility are associated with an increased risk of congenital anomalies in general ${ }^{50}$ and in particular with OAVS, as proposed previously. ${ }^{14,23,24}$ The higher maternal age observed among mothers of OAVS patients could be also related to the higher rate of reproductive difficulties.

It was suggested that maternal diabetes may also be associated with OAVS. ${ }^{25}$ It is estimated that $0.3 \%$ of all pregnant women have prepregnancy diabetes. ${ }^{51}$ We found the number of mothers with prepregnancy diabetes in OAVS pregnancies to be more than 10 times higher, supporting the hypothesis that diabetes is a risk factor for this developmental disorder.

\section{Study strengths and limitations}

This epidemiological population-based study is the largest to date and the only one in which data on all types of birth outcomes is included. The greatest strengths of this study are the large series of OAVS patients and the use of multiple sources of ascertainment, which made possible avoiding ascertainment bias found in the reports from specialised centres.

However, in spite of the use of the same methodology, the possible differences due to case ascertainment methods, data-coding practices and true differences in the risk of OAVS among different populations must be taken into consideration when combining epidemiological data from many different registries. For example, the average age at diagnosis varies according to the prenatal and early neonatal screening and follow-up practices in each region. The different prenatal ultrasound policies and possible differences in operators' skill and equipment can account for differences in prenatal detection rates among different registries. Few registries report only cases up to 1 week of life and could miss patients diagnosed later on with milder clinical presentation. Furthermore, there are differences in the completeness and accuracy of case description and in the level of genetic expertise. As registries are collecting limited set of routine data, we were not able to consider all possible aetiological factors.

Another limitation is that mild cases of isolated microtia and other minor ear anomalies are not included, which hampers comparison with some of the studies. However, caution should be exercised when comparing with other studies due to differences in methodology, sample size, biases in patient selection and level of investigations of internal organs/systems. 
The high rate of associated anomalies points to the need to perform an early screening of the heart, kidneys and spine in all infants born with this disorder. Early diagnosis, long-term multidisciplinary follow-up and genetic counselling of affected families are needed for optimal patient management.

\section{CONFLICT OF INTEREST}

The authors declare no conflict of interest.

\section{ACKNOWLEDGEMENTS}

This study is a part of the EUROCAT Joint Action funded by the EC, under the framework of EU Health Programme 2008-2013, Grant Agreement 20102204 (Executive Agency for Health and Consumers). We thank Dr Elizabeth S Draper, Dr Miriam Gatt, Dr Martin Haeusler, Dr Anna Latos-Bielenska,

Dr Christine Verellen-Dumoulin, Dr Carlos Matias Dias, Dr Vera Nelen and Dr Mary ÓMahony for providing data for the present study. We also thank the many people throughout Europe involved in providing and processing information, including affected families, clinicians, health professionals, medical record clerks and registry staff.

1 Goldenhar M: Associations malformatives de l'oeil et de l'oreille, en particulier le syndrome dermoïde epibulbaire-appendices auriculaires-fistula auris congenita et ses relations avec la dysostose mandibulo-faciale. J Genet Hum 1952; 1: 243-282.

2 Grabb WC: The first and second brachial arch syndromes. Plast Reconstr Surg 1965; 36: 485-508.

3 Hennekam RC, Krantz ID, Allanson JE: Gorlin's Syndromes of the Head and Neck. Oxford: Oxford University Press, 2010.

4 Rollnick BR, Kaye Cl, Nagatoshi K, Hauck W, Martin AO: Oculoauriculovertebral dysplasia and variants: phenotypic characteristics of 294 patients. Am J Med Genet 1987; 26: 361-375.

5 Tasse C, Böhringer S, Fischer S et al: Oculo-auriculo-vertebral spectrum (OAVS): clinical evaluation and severity scoring of 53 patients and proposal for a new classification. Eur J Med Genet 2005; 48: 397-411.

6 Rooryck C, Souakri N, Cailley D et al: Array-CGH analysis of a cohort of 86 patients with oculoauriculovertebral spectrum. Am J Med Genet A 2010; 152A: 1984-1989.

7 Brun A, Cailley D, Toutain J et al: $1.5 \mathrm{Mb}$ microdeletion in 15q24 in a patient with mild OAVS phenotype. Eur J Med Genet 2012; 55: 135-139.

8 Ou Z, Martin DM, Bedoyan JK et al: Branchiootorenal syndrome and oculoauriculovertebral spectrum features associated with duplication of SIX1, SIX6, and OTX2 resulting from a complex chromosomal rearrangement. Am J Med Genet A 2008; 146A: 2480-2489.

9 Northup JK, Matalon D, Hawkins JC et al: Pericentric inversion, inv(14)(p11.2q22.3), in a 9-month old with features of Goldenhar syndrome. Clin Dysmorphol 2010; 19 185-189.

10 Ballesta-Martínez MJ, López-González V, Dulcet LA, Rodríguez-Santiago B, Garcia-Miñaúr S, Guillen-Navarro E: Autosomal dominant oculoauriculovertebral spectrum and 14q23.1 microduplication. Am J Med Genet A. 2013; 161: 2030-2035.

11 Kelberman D, Tyson J, Chandler DC et al: Hemifacial microsomia: progress in understanding the genetic basis of a complex malformation syndrome. Hum Genet 2001; 109: 638-645.

12 Huang XS, Li X, Tan C et al: Genome-wide scanning reveals complex etiology of oculo-auriculo-vertebral spectrum. Tohoku J Exp Med 2010; 222: 311-318.

13 Fischer S, Lüdecke HJ, Wieczorek D, Böhringer S, Gillessen-Kaesbach G, Horsthemke B: Histone acetylation dependent allelic expression imbalance of BAPX1 in patients with the oculo-auriculo-vertebral spectrum. Hum Mol Genet 2006; 15: 581-587.

14 Wieczorek D, Ludwig M, Boehringer S, Jongbloet PH, Gillessen-Kaesbach G, Horsthemke B: Reproduction abnormalities and twin pregnancies in parents of sporadic patients with oculo-auriculo-vertebral spectrum/Goldenhar syndrome. Hum Genet 2007; 121: 369-376.

15 Stoll C, Viville B, Treisser A, Gasser B: A family with dominant oculoauriculovertebral spectrum. Am J Med Genet 1998; 78: 345-349.

16 Tasse C, Majewski F, Böhringer S et al: A family with autosomal dominant oculo-auriculo-vertebral spectrum. Clin Dysmorphol 2007; 16: 1-7.

17 Krause U: The syndrome of Goldenhar affecting two siblings. Acta Ophthalmol 1970; 48: 494-469.

18 Lacombe D, Battin J: Germinal mosaicism in oculo-auriculo-vertebral dysplasia? Am J Med Genet 1993; 46: 609-610.

19 Werler MM, Starr JR, Cloonan YK, Speltz ML: Hemifacial microsomia: from gestation to childhood. J Craniofac Surg Supp/ 2009; 20: 664-669.

20 Lessick M, Vasa R, Israel J: Severe manifestations of oculoauriculovertebral spectrum in a cocaine exposed infant. J Med Genet 1991; 28: 803-804.
21 Poswillo D: The pathogenesis of the first and second branchial arch syndrome. Oral Surg 1973; 35: 302-329.

22 Lawson K, Waterhouse N, Gault DT, Calvert ML, Botma M, Ng R: Is hemifacial microsomia linked to multiple maternities? Br J Plast Surg 2002; 55: 474-478.

23 Werler MM, Sheehan JE, Hayes C, Padwa BL, Mitchell AA, Mulliken JB: Demographic and reproductive factors associated with hemifacial microsomia. Cleft Palate Craniofac $\mathrm{J}$ 2004: 41: 494-550.

24 Jongbloet $\mathrm{PH}$ : Goldenhar syndrome and overlapping dysplasias, in vitro fertilisation and ovopathy. J Med Genet 1987; 24: 616-620.

25 Wang R, Martínez-Frías ML, Graham JM Jr: Infants of diabetic mothers are at increased risk for the oculo-auriculo-vertebral sequence: a case-based and case-control approach. J Pediatr 2002; 141: 611-617.

26 Morrison PJ, Mulholland HC, Craig BG, Nevin NC: Cardiovascular abnormalities in the oculo-auriculo-vertebral spectrum (Goldenhar syndrome). Am J Med Genet 1992; 44 . 425-428.

27 Boyd PA, Haeusler M, Barisic I, Loane M, Garne E, Dolk H: Paper 1: The EUROCAT network-organization and processes. Birth Defects Res A Clin Mol Teratol 2011; 91(Suppl1): S2-15.

28 Vento AR, LaBrie RA, Mulliken JB: The O.M.E.N.S. classification of hemifacial microsomia. Cleft Palate Craniofac J 1991; 28: 68-76.

29 Touliatou V, Fryssira H, Mavrou A, Kanavakis E, Kitsiou-Tzeli S: Clinical manifestations in 17 Greek patients with Goldenhar syndrome. Genet Couns 2006; 17: 359-370.

30 Araneta MR, Moore CA, Olney RS et al: Goldenhar syndrome among infants born in military hospitals to Gulf War veterans. Teratology 1997; 56: 244-251.

31 Stoll C, Roth MP, Dott B, Bigel P: Discordance for skeletal and cardiac defect in monozygotic twins. Acta Genet Med Gemellol 1984; 33: 501-504.

32 Melnick M: Hereditary hearing loss and ear dysplasia-renal adysplasia syndromes: syndrome delineation and possible pathogenesis. Birth Defects Orig Artic Ser 1980; 16: 59-72.

33 Gibson JN, Sillence DO, Taylor TK: Abnormalities of the spine in Goldenhar's syndrome. J Pediatr Orthop 1996; 16: 344-349.

34 Digilio MC, Calzolari F, Capolino R et al: Congenital heart defects in patients with oculo-auriculo-vertebral spectrum (Goldenhar syndrome). Am J Med Genet A 2008; 146A: $1815-1819$.

35 Greenwood RD, Rosenthal A, Sommer A, Wolff G, Craenen J: Cardiovascular malformations in oculoauriculovertebral dysplasia (Goldenhar syndrome). J Pediatr 1974; 85: 816-818.

36 Kumar A, Friedman JM, Taylor GP, Patterson MW: Pattern of cardiac malformation in oculoauriculovertebral spectrum. Am J Med Genet 1993; 46: 423-426.

37 Ritchey ML, Norbeck J, Huang C, Keating MA, Bloom DA: Urologic manifestations of Goldenhar syndrome. Urology 1994; 43: 88-91.

38 Rosa RF, Graziadio C, Lenhardt R, Alves RP, Paskulin GA, Zen PR: Central nervous system abnormalities in patients with oculo-auriculo-vertebral spectrum (Goldenhar syndrome). Arq Neuropsiquiatr 2010; 68: 98-102.

39 Gabbett MT, Robertson SP, Broadbent R, Aftimos S, Sachdev R, Nezarati MM: Characterizing the oculoauriculofrontonasal syndrome. Clin Dysmorph 2008; 17: 79-85.

40 Evans KN, Gruss JS, Khanna PC, Cunningham ML, Cox TC, Hing AV: Oculoauriculofrontonasal syndrome: case series revealing new bony nasal anomalies in an old syndrome. Am J Med Genet A 2013; 161: 1345-1353.

41 Bergmann C, Zerres K, Peschgens T, Senderek J, Hörnchen H, Rudnik-Schöneborn S: Overlap between VACTERL and hemifacial microsomia illustrating a spectrum of malformations seen in axial mesodermal dysplasia complex (AMDC). Am J Med Genet $A$ 2003; 121A: 151-155

42 Castori M, Brancati F, Rinaldi R et al: Antenatal presentation of the oculo-auriculovertebral spectrum (OAVS). Am J Med Genet A 2006; 140: 1573-1579.

43 Kushnick T, Colondrillo M: 49, XXXXY patient with hemifacial microsomia. Clin Genet 1975; 7: 442-448.

44 Rao VA, Kaliaperumal S, Subramanyan T, Rao KR, Bhargavan R: Goldenhar's sequence with associated juvenile glaucoma in Turner's syndrome. Indian J Ophthalmol 2005; 53: 267-268

45 Pison G, D'Addato AV: Frequency of twin births in developed countries. Twin Res Hum Genet 2006; 9: 250-259.

46 de Mouzon J, Goossens V, Bhattacharya S et al: European IVF-Monitoring (EIM); Consortium for the European Society on Human Reproduction and Embryology (ESHRE). Assisted reproductive technology in Europe, 2007: results generated from European registers by ESHRE. Hum Reprod 2012; 27: 954-966.

47 Ferraris S, Silengo M, Ponzone A, Perugini L: Goldenhar anomaly in one of triplets derived from in vitro fertilization. Am J Med Genet 1999; 84: 167-168.

48 Roesch C, Steinbicker V, Korb C, von Rohden L, Schmitt J: Goldenhar anomaly in one triplet derived from intracytoplasmic sperm injection (ICSI). Am J Med Genet 2001; 101: 82-83.

49 Gittins V, Kasraie J: Case report: Goldenhar syndrome following donor oocyte IVF. J Assist Reprod Genet 2010; 27: 561-563.

50 Boyle B, McConkey R, Garne E et al: Trends in the prevalence, risk and pregnancy outcome of multiple births with congenital anomaly: a registry-based study in 14 European countries 1984-2007. BJOG 2013; 120: 707-716.

51 Garne E, Loane M, Dolk H et al: Spectrum of congenital anomalies in pregnancies with pregestational diabetes. Birth Defects Res A Clin Mol Teratol 2012; 94: $134-140$ 